Article

\title{
Combination of Data-Driven Active Disturbance Rejection and Takagi-Sugeno Fuzzy Control with Experimental Validation on Tower Crane Systems
}

\author{
Raul-Cristian Roman ${ }^{1}$ (), Radu-Emil Precup ${ }^{1, * \mathbb{C}}$, Emil M. Petriu ${ }^{2}$ and Florin Dragan ${ }^{1}$ \\ 1 Department of Automation and Applied Informatics, Politehnica University of Timisoara, Bd. V. Parvan 2, \\ 300223 Timisoara, Romania; raul-cristian.roman@upt.ro (R.-C.R.); florin.dragan@upt.ro (F.D.) \\ 2 School of Electrical Engineering and Computer Science, University of Ottawa, 800 King Edward, \\ Ottawa, ON K1N 6N5, Canada; petriu@uottawa.ca \\ * Correspondence: radu.precup@aut.upt.ro; Tel.: +40-256-403-229
}

Received: 24 March 2019; Accepted: 22 April 2019; Published: 24 April 2019

\begin{abstract}
In this paper a second-order data-driven Active Disturbance Rejection Control (ADRC) is merged with a proportional-derivative Takagi-Sugeno Fuzzy (PDTSF) logic controller, resulting in two new control structures referred to as second-order data-driven Active Disturbance Rejection Control combined with Proportional-Derivative Takagi-Sugeno Fuzzy Control (ADRC-PDTSFC). The data-driven ADRC-PDTSFC structure was compared with a data-driven ADRC structure and the control system structures were validated by real-time experiments on a nonlinear Multi Input-Multi Output tower crane system (TCS) laboratory equipment, where the cart position and the arm angular position of TCS were controlled using two Single Input-Single Output control system structures running in parallel. The parameters of the data-driven algorithms were tuned in a model-based way using a metaheuristic algorithm in order to improve the efficiency of energy consumption.
\end{abstract}

Keywords: Active Disturbance Rejection Control; data-driven control; fuzzy control; second-order data-driven Active Disturbance Rejection Control merged with proportional-derivative Takagi-Sugeno Fuzzy Control; tower crane systems

\section{Introduction}

In this paper the authors propose to merge two techniques, the second-order data-driven Active Disturbance Rejection Control (ADRC) and the proportional-derivative Takagi-Sugeno Fuzzy (PDTSF) logic control in two ways resulting in two control structures referred to as second-order data-driven Active Disturbance Rejection Control combined with Proportional-Derivative Takagi-Sugeno Fuzzy Control (ADRC-PDTSFC). The purpose of these new combinations is to improve the overall performance of control system (CS) structures.

Two ADRC-PDTSFC structures are proposed in the next sections. For the first ADRC-PDTSFC structure (ADRC-PDTSFC1) the proportional-derivative (PD) component in data-driven ADRC is fuzzified using a PDTSF logic controller. For the second ADRC-PDTSFC structure (ADRC-PDTSFC2) a PDTSF logic controller is added to the ADRC algorithm. To determine if the proposed ADRC-PDTSFC structures perform better than the ADRC structure, several comparison case studies are considered, where the performance of the CS with ADRC algorithm is compared with the performance of the CS with ADRC-PDTSFC1 and ADRC-PDTSFC2. To have a fair comparison between these CSs, the parameters of ADRC, ADRC-PDTSFC1 and ADRC-PDTSFC2 are tuned in a model-based way using the Grey Wolf Optimizer (GWO) algorithm, which solves an optimization problem characterized by an objective function expressed by the weighted sum of squared control errors and squared control 
signals. This formulation of the objective functions ensures a reduced energy consumption and thus energy efficiency. The experimental validation is conducted on a nonlinear Multi Input-Multi Output (MIMO) three-degrees-of-freedom tower crane system (TCS). Three values of the penalty factor in the weighted objective function are considered, resulting in three sets of experimental scenarios.

ADRC [1-4] is one of the most popular data-driven techniques along with Model-Free Adaptive Control [5-9], Model-Free Control [10-14] or Virtual Reference Feedback Tuning [15-18]. The main advantage that made data-driven techniques so popular is that they use only the input/output data from the process. This advantage of data-driven control (in the tuning) can be very useful when the accurate mathematical model of the process is impossible or very hard to be determined or when the plant has strong nonlinearities.

Data-driven ADRC algorithms were successfully applied to numerous types of processes, such as double-switch buck-boost converters [19], microgrid [20], pendulum-cart systems [21], fractional-order systems [22], interior permanent magnet synchronous motor drives [23], Direct Current (DC) torque motors [24], linear induction motors [25], Oxygen masks [26], hydraulic servo systems [27] and benchmark systems [28].

One of the most successful and commonly used control techniques is fuzzy logic. Some TCS applications with fuzzy logic control are $H_{\infty}$ based on adaptive fuzzy control technique [29,30], anti-swing controller designed using a time-delayed feedback of the load swing angle and an anti-swing fuzzy logic controller [31], gain-scheduling anti-swing controller that employs fuzzy clustering techniques [32], fuzzy logic for selecting the best crane [33], anti-swing combined with fuzzy control [34], fuzzy logic with sensorless payload deflection feedback [35] and Mamdani fuzzy logic controller [36].

The literature reports several combinations of ADRC and fuzzy logic, namely experimental validation on a brushless DC motor in [37], simulation results for a ship course in [38], simulation results for a permanent magnet synchronous motor in [39], permanent magnet synchronous motor sensorless control system for electric vehicle validated by simulation results in [40], simulation results for a flying boat in [41], simulated and experimental validation for permanent magnet synchronous motor servo system in [42], simulated and experimental validation of three motor synchronous system in [43], simulated validation of attitude maneuver control of a spacecraft in [44], simulated validation of insulin infusion in type 1 diabetic patients in [45] or electrical actuation system validated through simulation results in [46].

The TCS nonlinear laboratory equipment is very practical because it is actually a small-scale representation of an industrial tower crane used in civil engineering. However, for the moment the state of the art is very poor when discussing about controllers designed for TCS. Some TCS applications with different types of controllers include simulation and experimental results using a tensor product model transformation-based nonlinear feedback controller, with an additional neural network-based friction compensator [47], simulation results using recurrent neural networks evolved by evolutionary algorithms [48], simulation and experimental results using gain scheduling feedback control [49], simulation and experimental results using nonlinear model predictive control [50], experimental results with input-shaping control to suppress double-pendulum payload oscillations [51], experimental results with adaptive control [52], experimental results for a nonlinear anti-swing feedback controller with an integral term [53], experimental results with hierarchical artificial neural network-based adaptive fuzzy logic [54].

The new contributions of this paper are:

- Two control structures (ADRC-PDTSFC1 and ADRC-PDTSFC2) obtained by the combination of ADRC and Takagi-Sugeno fuzzy control;

- Experimental validation of the proposed ADRC-PDTSFC1 and ADRC-PDTSFC2 structures on the TCS equipment, a process with nonlinearities;

- Comparison between the ADRC-PDTSFC structures; 
- Optimal tuning of ADRC, ADRC-PDTSFC1 and ADRC-PDTSFC2 parameters in terms of using more efficient the energy consumption.

The design of the proposed controllers in the following sections is accomplished by following the steps:

- In the first step an extended Luenberger state observer was developed to estimate the not directly observable effects of the neglected dynamics as a disturbance. By the use of this estimation an ADRC controller was developed within the frames of the LTI systems with proportional and derivative feedback terms in discrete time approximation.

- In the next step the ADRC controller was further improved by fuzzifying the PD terms in the first version ("ADRC-PDTSFC1 structure") in a Two Inputs-Single Output Fuzzy Controller with a relatively simple rule-base using $2 \times 3$ fuzzy membership functions.

- The second version ("ADRC-PDTSFC2 structure") is a modification of the same initial ADRC controller, too, by adding further PD feedback terms to the original ones before fuzzifying them. This latter structure has more independent parameters than the previous one.

- In the case of both versions the so-obtained "control models" (containing the parameters of the membership functions) were inserted into an optimal controller in which the sum of the squares of the tracking errors plus the sum of the squares of the control signals weighted with a "penalty factor" were minimized for three different penalty factors: (a) a big value that made the precise trajectory tracking impossible; (b) a rather reasonable value that allowed acceptable tracking by consuming up more energy by the controller; and (c) a small value that only slightly prohibited the energy consumption of the control process.

- In the last step experimental investigation of the operation of these controllers was carried out.

The paper is organized as follows: a short overview of second-order data-driven ADRC is presented in the next section. Section 3 offers the design approach of ADRC-PDTSFC structures. Section 4 describes the nonlinear TCS laboratory equipment used for experimental validation. The real time experiments that validate the ADRC, ADRC-PDTSFC1 and ADRC-PDTSFC2 structures are given in Section 5. The conclusions with the advantages and the disadvantages of the proposed structure are highlighted in Section 6.

\section{Data-Driven Second-Order ADRC Structure}

The design of the second order ADRC algorithm starts with the second-order Single Input-Single Output (SISO) process model [1-3]:

$$
\tau^{2} \ddot{y}(t)+2 \omega \tau \dot{y}(t)+y(t)=\kappa u(t)+\eta(t),
$$

where $\tau \in R$ is the natural period of oscillation of the process, $\omega \in R$ is the damping factor of the process, $k \in R$ is the process gain, $u(t) \in R$ is the continuous-time control signal, $y(t) \in R$ is the continuous-time controlled output and in $\eta(t) \in R$ is the unknown disturbance that also includes the unmodeled dynamics of the process.

Using the notation $a=\frac{\mathrm{K}}{\tau^{2}}, a \in R$ and splitting it into $a=a_{0}+\Delta a$, with $a_{0} \in R$ as a known estimate and $\Delta a \in R$ as the unknown modelling error, the second-order SISO process in (1) is rewritten as:

$$
\ddot{y}(t)=-\frac{2 \omega \dot{y}(t)}{\tau}-\frac{y(t)}{\tau^{2}}+\frac{\eta(t)}{\tau^{2}}+\Delta a u(t)+a_{0} u(t) .
$$

Considering a generalized disturbance term $f(t) \in R$ that may contain terms that convey inconvenient coupling with $y(t), \dot{y}(t), \dot{y}(t)$ that are "hidden" by $\eta(t), f(t)$ depends on the unknown 
disturbances and unmodeled dynamics of the process and the unknown modelling error, with the notation

$$
f(t)=-\frac{2 \omega \dot{y}(t)}{\tau}-\frac{y(t)}{\tau^{2}}+\frac{\eta(t)}{\tau^{2}}+\Delta a u(t),
$$

the process model resulted after substituting the generalized disturbance term in (3) into the second-order SISO process in (2) results as a disturbed double integrator:

$$
\ddot{y}(t)=a_{0} u(t)+f(t) .
$$

The state-space model of the disturbed double integrator process model in (4) is [1-3]:

$$
\begin{aligned}
& {\left[\begin{array}{l}
\dot{x}_{1}(t) \\
\dot{x}_{2}(t) \\
\dot{x}_{3}(t)
\end{array}\right]=\left[\begin{array}{lll}
0 & 1 & 0 \\
0 & 0 & 1 \\
0 & 0 & 0
\end{array}\right]\left[\begin{array}{c}
x_{1}(t) \\
x_{2}(t) \\
x_{3}(t)
\end{array}\right]+\left[\begin{array}{c}
0 \\
a_{0} \\
0
\end{array}\right] u(t)+\left[\begin{array}{l}
0 \\
0 \\
1
\end{array}\right] \dot{f}(t),} \\
& y(t)=\left[\begin{array}{lll}
1 & 0 & 0
\end{array}\right]\left[\begin{array}{c}
x_{1}(t) \\
x_{2}(t) \\
x_{3}(t)
\end{array}\right]
\end{aligned}
$$

with $x_{1}(t)=y(t), x_{2}(t)=\dot{y}(t)$ and $x_{3}(t)=f(t)$ used as substitutions.

An extended Luenberger state observer (ELSO) is used to approximate $\dot{f}(t)$ because its value cannot be measured. Therefore, in the ELSO design, $u(t)$ and $y(t)$ are considered as ELSO inputs and the state estimates $\hat{x}_{1}(t), \hat{x}_{2}(t)$ and $\hat{x}_{3}(t)$ are used to approximate the values of $y(t), \dot{y}(t)$ and $f(t)$. The gain matrix $\mathbf{L}=\left[l_{1} l_{2} l_{3}\right]^{T} \in R^{3 \times 1}$ (column matrix, where $T$ indicates matrix transposition) will be used in order to provide the estimate of the state variables in (5). The dynamic model of ELSO is [1-3]:

$$
\begin{aligned}
& \underbrace{\left[\begin{array}{c}
\dot{\hat{x}}_{1}(t) \\
\dot{\hat{x}}_{2}(t) \\
\dot{\hat{x}}_{3}(t)
\end{array}\right]}_{\dot{\hat{\mathbf{x}}}(t)}=\underbrace{\left[\begin{array}{ccc}
0 & 1 & 0 \\
0 & 0 & 1 \\
0 & 0 & 0
\end{array}\right]\left[\begin{array}{c}
\hat{x}_{1}(t) \\
\hat{x}_{2}(t) \\
\hat{x}_{3}(t)
\end{array}\right]}_{\mathbf{A}}+\underbrace{\left[\begin{array}{c}
0 \\
a_{0} \\
0
\end{array}\right]}_{\hat{\mathbf{x}}(t)} u(t)+\underbrace{\left[\begin{array}{c}
l_{1} \\
l_{2} \\
l_{3}
\end{array}\right]}_{\mathbf{B}}(y(t)-\hat{y}(t)), \\
& \hat{y}(t)=\underbrace{\left[\begin{array}{lll}
1 & 0 & 0
\end{array}\right]}_{\mathbf{C}} \underbrace{\left[\begin{array}{c}
\hat{x}_{1}(t) \\
\hat{x}_{2}(t) \\
\hat{x}_{3}(t)
\end{array}\right]}_{\hat{\mathbf{x}}(t)}
\end{aligned}
$$

where $\mathbf{A} \in R^{3 \times 3}, \mathbf{B} \in R^{3 \times 1}, \mathbf{C} \in R^{1 \times 3}$ are ELSO matrices. Substituting $\hat{x}_{1}(t)$ with $\hat{y}(t)$, (6) becomes:

$$
\begin{aligned}
& {\left[\begin{array}{c}
\dot{\hat{x}}_{1}(t) \\
\dot{\hat{x}}_{2}(t) \\
\dot{\hat{x}}_{3}(t)
\end{array}\right]=\underbrace{\left[\begin{array}{ccc}
-l_{1} & 1 & 0 \\
-l_{2} & 0 & 1 \\
-l_{3} & 0 & 0
\end{array}\right]}_{\text {A-LC }}\left[\begin{array}{c}
\hat{x}_{1}(t) \\
\hat{x}_{2}(t) \\
\hat{x}_{3}(t)
\end{array}\right]+\left[\begin{array}{c}
0 \\
a_{0} \\
0
\end{array}\right] u(t)+\left[\begin{array}{l}
l_{1} \\
l_{2} \\
l_{3}
\end{array}\right] y(t)} \\
& \hat{y}(t)=\left[\begin{array}{lll}
1 & 0 & 0
\end{array}\right]\left[\begin{array}{c}
\hat{x}_{1}(t) \\
\hat{x}_{2}(t) \\
\hat{x}_{3}(t)
\end{array}\right] .
\end{aligned}
$$

The elements of gain $\mathbf{L}$ can be determined by arbitrarily choosing the eigenvalues of the matrix $(\mathbf{A}-\mathbf{L C})$ in the left half-pane. 
The discrete-time model of ELSO accounting for the zero-order hold element is

$$
\begin{aligned}
& {\left[\begin{array}{l}
\hat{x}_{1}(k+1) \\
\hat{x}_{2}(k+1) \\
\hat{x}_{3}(k+1)
\end{array}\right]=\mathbf{A}_{d}\left[\begin{array}{l}
\hat{x}_{1}(k) \\
\hat{x}_{2}(k) \\
\hat{x}_{3}(k)
\end{array}\right]+\mathbf{B}_{d}\left[\begin{array}{l}
u(k) \\
y(k)
\end{array}\right],} \\
& \hat{y}(k)=\mathrm{C}\left[\begin{array}{c}
\hat{x}_{1}(k) \\
\hat{x}_{2}(k) \\
\hat{x}_{3}(k)
\end{array}\right] .
\end{aligned}
$$

The discrete-time second-order control law specific to ADRC is:

$$
u(k)=K_{1} \underbrace{\left(y^{*}(k)-\hat{x}_{1}(k)\right)}_{\hat{e}(k)}+K_{2} \underbrace{\left(\Delta y^{*}(k)-\hat{x}_{2}(k)\right)}_{\Delta \hat{e}(k)}-\frac{\hat{x}_{3}(k)}{a_{0}},
$$

where $\Delta y^{*}(k)=y^{*}(k)-y^{*}(k-1), y^{*}(k) \in R$ is the desired reference trajectory, $\hat{e}(k) \in R$ is the approximate tracking error, $\Delta \hat{e}(k)=\hat{e}(k)-\hat{e}(k-1)$, and $K_{1}$ and $K_{2}$ are the parameters of the discrete-time second-order ADRC control law. Equation (9) indicates that we deal with a modified PD controller, so $K_{1}$ and $K_{2}$ can also be seen as the parameters of a PD component in the control law [1-3].

As shown in [55], the stability is guaranteed for a second-order system if there exists a Lyapunov function that satisfies an inequality, where the partial derivatives of the Lyapunov function is smaller than a user-chosen parameter. Then if under a disturbance another inequality is satisfied, the disturbed system will still be asymptotically stable.

The control system structure with second-order discrete-time data-driven ADRC algorithm is presented in Figure 1.

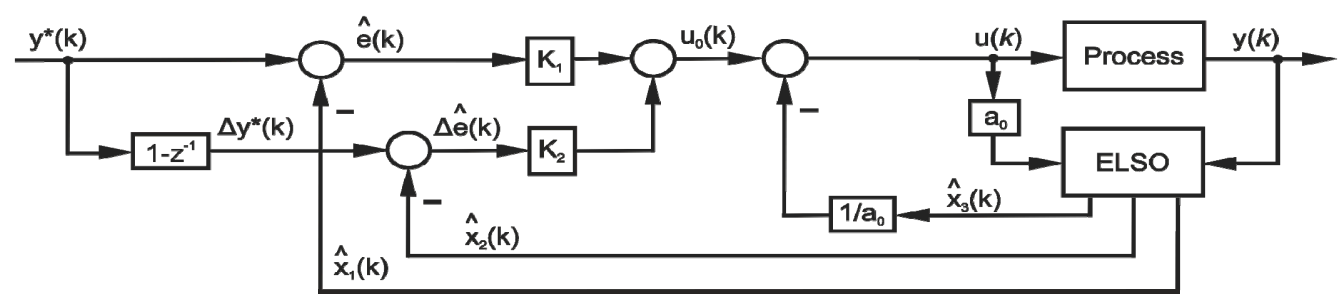

Figure 1. The control system structure with second-order discrete-time Active Disturbance Rejection Control (ADRC) algorithm.

\section{Second-Order Data-Driven ADRC-PDTSFC Structures}

\subsection{Second-Order Data-Driven ADRC-PDTSFC1 Structure}

The discrete-time second order control law specific to data-driven ADRC-PDTSFC1 is a combination of the discrete-time second order data-driven ADRC control law in (9) and a PD Takagi-Sugeno Fuzzy logic controller. The PD component in ADRC-PDTSFC1 structure is fuzzified using a Takagi-Sugeno Fuzzy logic controller leading to the following control law:

$$
u(k)=\chi(k)-\frac{\hat{x}_{3}(k)}{a_{0}},
$$

where the component $\chi(k)$ is replaced by the PDTSFC1 component, and it is designed using the recurrent equation of the PD component in (9) [56]:

$$
\Phi(k)=K_{1}\left(y^{*}(k)-\hat{x}_{1}(k)\right)+K_{2}\left(\Delta y^{*}(k)-\hat{x}_{2}(k)\right)=K_{1} \hat{e}(k)+K_{2} \Delta \hat{e}(k) .
$$


This PDTSFC1 component is built around a Two Inputs-Single Output Fuzzy Controller (TISO-FC) as shown in Figure 2, where $B_{\hat{e}}$ and $B_{\Delta \hat{e}}$ are the parameters of the membership functions, and the SUM and PROD operators are used in the inference engine of the fuzzy component [56]. The rule base consists of nine rules presented in Table 1, with the rule consequents:

$$
\chi_{i}(k)=\gamma_{i} \Phi(k), i=1 \ldots 3, \gamma_{i}>0 .
$$
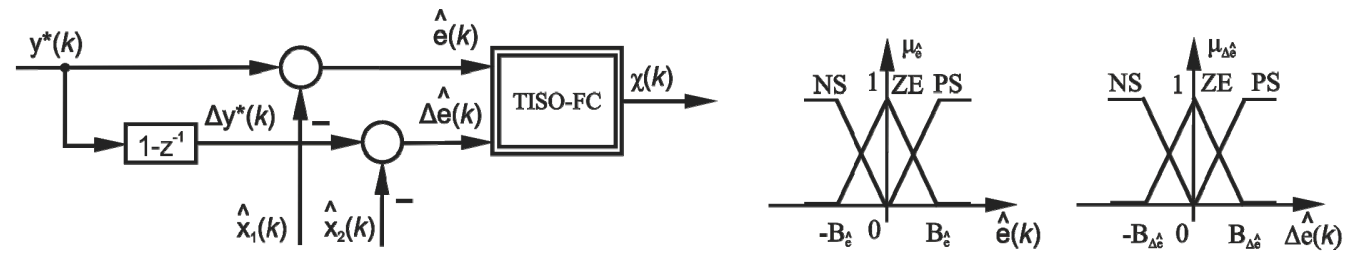

Figure 2. The block diagram of the proportional-derivative Takagi-Sugeno Fuzzy control (PDTSFC)1 component and the input membership functions.

Table 1. The rule base of the ADRC-PDTSFC controller.

\begin{tabular}{cccc}
\hline$\hat{y}(\boldsymbol{e})$ & & & \\
\cline { 1 - 1 } $\boldsymbol{y} \hat{\boldsymbol{e}}(\boldsymbol{k})$ & NS & ZE & PS \\
\cline { 1 - 1 } PS & & & \\
ZE & $\chi_{2}(k)$ & $\chi_{2}(k)$ & $\chi_{3}(k)$ \\
NS & $\chi_{2}(k)$ & $\chi_{2}(k)$ & $\chi_{1}(k)$ \\
$\chi_{2}(k)$ & $\chi_{2}(k)$ \\
\hline
\end{tabular}

Table 1, (11) and (12) lead to the conclusion that the PDTSFC1 component is practically a nonlinear combination of three discrete-time PD controllers placed in the rule consequents, which change according to the fired rules. The main purpose of the parameter $\gamma_{i}$ is used to adjust the overshoot of the CS with the ADRC-PDTSFC1 technique for TCS control [56].

The control system structure with second-order discrete-time ADRC-PDTSFC1 algorithm is presented in Figure 3.

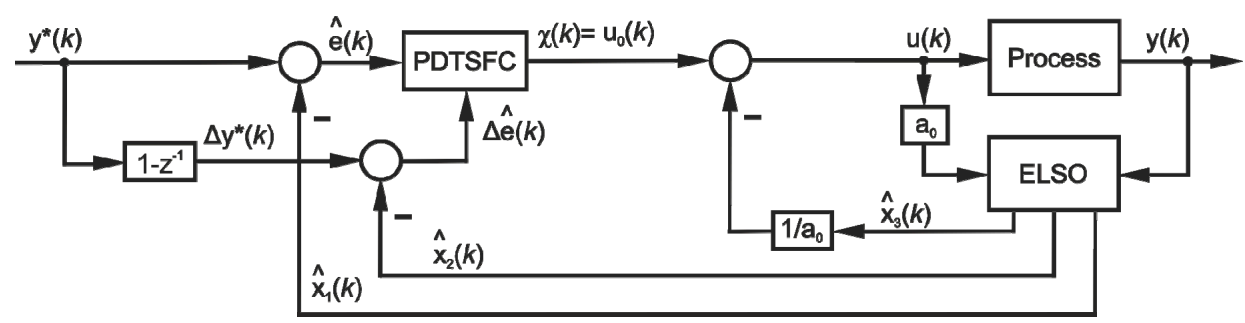

Figure 3. The control system structure with second-order discrete-time ADRC algorithm.

\subsection{Second-Order Data-Driven ADRC-PDTSFC2 Structure}

The discrete-time second-order control law specific to data-driven ADRC-PDTSFC2 is also a combination of the discrete-time second order ADRC control law in (9) and a PDTSF logic controller. A PD component is added to the control law as follows:

$$
\Phi(k)=K_{3} \hat{e}(k)+K_{4} \Delta \hat{e}(k),
$$

and it is next fuzzified using a Takagi-Sugeno fuzzy logic controller and added to the ADRC law in (9) leading to the following control law:

$$
u(k)=K_{1}\left(y^{*}(k)-\hat{x}_{1}(k)\right)+K_{2}\left(\Delta y^{*}(k)-\hat{x}_{2}(k)\right)-\frac{\hat{x}_{3}(k)}{a_{0}}+\chi(k),
$$


where the component $\chi(k)$ is replaced by the PDTSFC2 component, resulting in the combined ADRC-PDTSFC2 control law.

As in the previous case, the PDTSFC2 component is built around a TISO-FC respecting the representation given in Figure 2. Defining again the parameters $B_{\hat{e}}$ and $B_{\Delta \hat{e}}$ of the input membership functions, using the same inference engine of the fuzzy component that makes use of the SUM and PROD operators [56], the rule base is the same, it consists of nine rules presented in Table 1 with $\gamma_{i}$ in (12) used to adjust the overshoot of the CS with the ADRC-PDTSFC2 technique for TCS control [56].

The control system structure with second-order discrete-time ADRC-PDTSFC2 algorithm is presented in Figure 4.

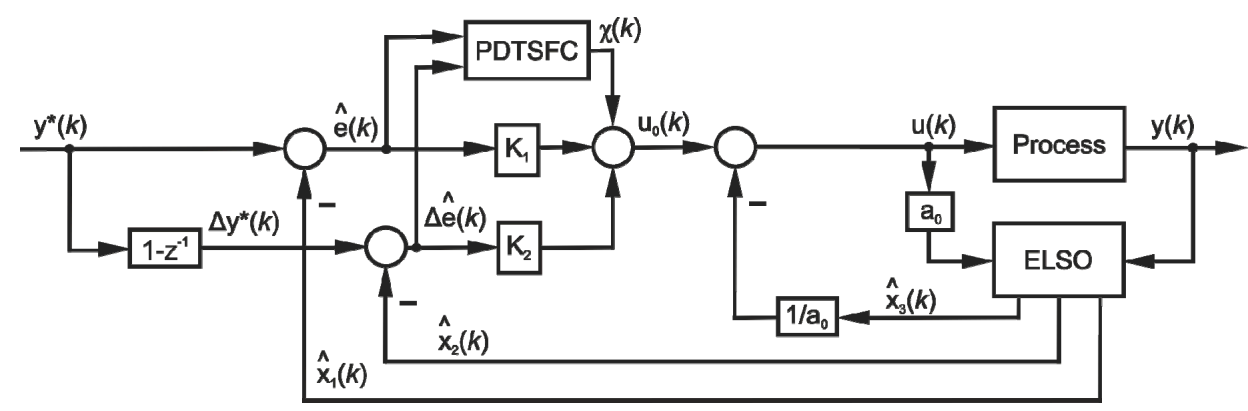

Figure 4. The control system structure with second-order discrete-time ADRC algorithm.

\section{The Nonlinear TCS Laboratory Equipment}

All ADRC, ADRC-PDTSFC1 and ADRC-PDTSFC2 controllers are validated experimentally on TCS, where the cart position and the arm angular position are controlled using two SISO loops running in parallel. All experiments are conducted starting with zero initial conditions. The nonlinear state-space model that describes the behavior of the TCS laboratory equipment is [57]:

$$
\begin{aligned}
& \dot{x}_{1}=x_{5} \\
& \dot{x}_{2}=x_{6} \\
& \dot{x}_{3}=x_{7} \\
& \dot{x}_{4}=x_{8} \\
& \dot{x}_{5}=-\frac{1}{2 L}\left(2 g \cos x_{2} \sin x_{1}+4 x_{7} x_{8} \cos x_{1}-L x_{8}^{2} \sin \left(2 x_{1}\right) \cos ^{2} x_{2}-2 x_{3} x_{8}^{2} \sin x_{1} \sin x_{2}\right. \\
& \left.-4 L x_{6} x_{8} \cos x_{2} \cos ^{2} x_{1}+L x_{6}^{2} \sin \left(2 x_{1}\right)+2 \sin x_{1} \sin x_{2} u_{c}+2 x_{3} \cos x_{1} u_{\theta}-2 L \sin x_{2} u_{\theta}\right), \\
& \dot{x}_{6}=-\frac{1}{L \cos x_{1}}\left(g \sin x_{2}+x_{3} x_{8}^{2} \cos x_{2}-L x_{8}^{2} \sin x_{2} \cos x_{1} \cos x_{2}+2 L x_{5} x_{8} \cos x_{1} \cos x_{2}\right. \\
& \left.-2 L x_{5} x_{6} \sin x_{1}-\cos x_{2} u_{c}+L \sin x_{1} \cos x_{2} u_{\theta}\right), \\
& \dot{x}_{7}=u_{c}, \\
& \dot{x}_{8}=u_{\theta} \\
& y_{c}=x_{3} \\
& y_{\theta}=x_{4}
\end{aligned}
$$

where $x_{\omega}$ is the cart position, $\theta$ is the arm angular position, $g=9.8067$ is the gravitational acceleration, $x_{1}=\beta, x_{2}=\alpha, \alpha$ and $\beta$ are the angles that describe the payload position in $x$-z plane, $L$ is the lift's line length $L=0.8$, parameter $L$ is not the same with gain matrix $\mathbf{L} \in R^{3 \times 1}$ defined in Section 2, $u_{c}$ and $u_{\theta}$ are the control signals for cart position control and arm angular position control, respectively, that is, the Pulse Width Modulation (PWM) duty cycle of the cart position and arm angular position direct current (DC) motors, the control limit values of $u_{c}$ and $u_{\theta}$ are limited by the PWM duty cycle between $[-1,1], x_{3}=x_{\omega}, x_{4}=\theta, x_{5}=\dot{\beta}, x_{6}=\dot{\alpha}, x_{7}=\dot{x}_{\omega}, x_{8}=\dot{\theta}, u_{c}=\ddot{x}_{\omega}, u_{\theta}=\ddot{\theta}$, and the outputs 
are the cart position $y_{c}(\mathrm{~m})$ with the lower and the upper limits $[-0.25,0.25]$ and the arm angular position $y_{\theta}(\mathrm{rad})$ with the lower and the upper limits $[-1.57,1.57]$. The diagram which shows the communication between the personal computer (for digital control) and the TCS laboratory equipment and the graphical definition of main variables in (15) are presented in Figure 5.

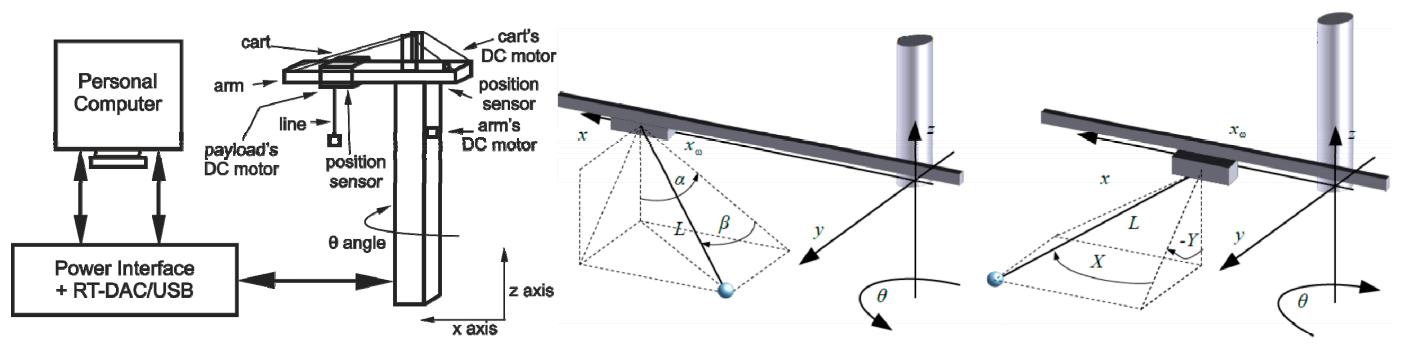

Figure 5. The tower crane system (TCS) block diagram.

As Figure 5 shows, the communication between the personal computer and the TCS laboratory equipment is ensured through a power interface unit, a real-time data acquisition and a control universal bus called RT-DAC/USB2 board, where the PWM control logic is stored in a XILINX chip [57]. The software pack provided by [57] called TowerCrane Toolbox also ensures the communication between the personal computer and the TCS laboratory equipment.

The block diagram of the MIMO control system structure that consists of two SISO control systems for separate cart position control and arm position control is given in Figure 6. Figure 6 illustrates the two SISO controllers, that is, cart position controller and arm angular position controller, with ADRC, ADRC-PDTSFC1 or ADRC-PDTSFC2 algorithms, the parameter vector $\boldsymbol{\Lambda}_{c}$ of cart position controller, the parameter vector $\Lambda_{\theta}$ of arm angular position controller, the reference input $y_{c}^{*}(\mathrm{~m})$ for cart position control (the set-point for $y_{c}$ ), the reference input $y_{\theta}^{*}(\mathrm{rad})$ for angular position control (the set-point for $\left.y_{\theta}\right)$, the estimated control error $\hat{e}_{c}(k)=y_{c}^{*}-\hat{x}_{1 c}$ for cart position control, the estimated control error $\hat{e}_{\theta}(k)=y_{\theta}^{*}-\hat{x}_{1 \theta}$ for arm angular position control. The control error $e_{c}(k)=y_{c}^{*}(k)-y_{c}(k)$ for cart position control and the control error $e_{\theta}(k)=y_{\theta}^{*}(k)-y_{\theta}(k)$ for arm angular position control are used in the next section in the definition of the objective function as part of the optimization problem for optimal tuning of controller parameters.

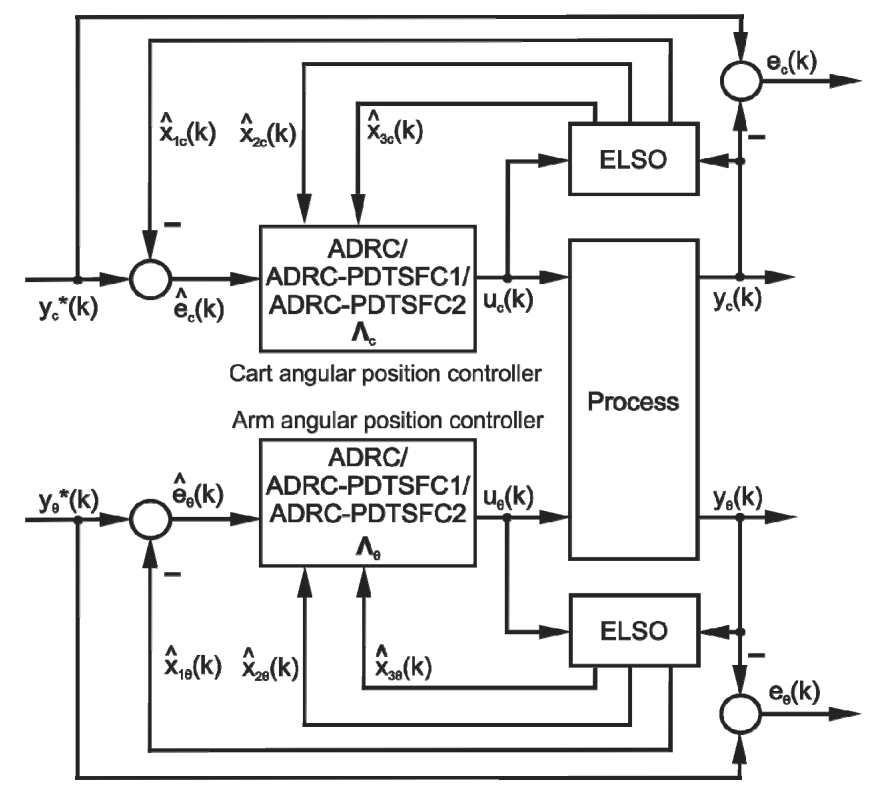

Figure 6. The Multi Input-Multi Output (MIMO) control system block diagram. 


\section{Experimental Results}

This section is dedicated to the presentation of three case studies and also experimental scenarios to validate the new controllers on TCS laboratory equipment in order to control the cart position and the arm angular position. In all experimental scenarios the parameters of the CS with ADRC controller, the CS with ADRC-PDTSFC1 controller and the CS with ADRC-PDTSFC2 controller are optimally tuned in a model-based way using a metaheuristic GWO algorithm [58-60] that solves the optimization problem:

$$
\boldsymbol{\Lambda}^{*}=\arg \min _{\boldsymbol{\Lambda}} J_{e, u}(\boldsymbol{\Lambda}), J_{e, u}(\boldsymbol{\Lambda})=\frac{1}{N} \sum_{k=1}^{N}\left[e_{c}^{2}(k, \boldsymbol{\Lambda})+e_{\theta}^{2}(k, \boldsymbol{\Lambda})+\lambda\left(u_{c}^{2}(k, \boldsymbol{\Lambda})+u_{\theta}^{2}(k, \boldsymbol{\Lambda})\right)\right],
$$

where $\boldsymbol{\Lambda}=\left[\boldsymbol{\Lambda}_{c} \boldsymbol{\Lambda}_{\theta}\right]^{T}$ is a vector variable (column matrix) that contains the tunable parameters of the ADRC, ADRC-PDTSFC1 or ADRC-PDTSFC2 control laws, with the subscripts $c$ and $\theta$ related to cart position and arm angular position, respectively, $\Lambda$ is inserted as an additional argument to the variables in (16) in order to point out that all variables depend on the controller parameters gathered in $\Lambda, \Lambda^{*}=\left[\boldsymbol{\Lambda}_{c}^{*} \boldsymbol{\Lambda}_{\theta}^{*}\right]^{T}$ is a vector variable (column matrix) that contains the optimal parameters of ADRC, ADRC-PDTSFC1 or ADRC-PDTSFC 2 control laws, $\Lambda$ contains the tunable parameters of ADRC control law expressed as:

$$
\begin{aligned}
& \boldsymbol{\Lambda}_{c}=\left[K_{1 c} K_{2 c} a_{0 c}\right]^{T}, \\
& \boldsymbol{\Lambda}_{\theta}=\left[K_{1 \theta} K_{2 \theta} a_{0 \theta}\right]^{T},
\end{aligned}
$$

the tunable parameters of ADRC-PDTSFC1 control law are grouped in the matrices:

$$
\begin{aligned}
& \boldsymbol{\Lambda}_{c}=\left[a_{0 c} \gamma_{1 c} \gamma_{2 c} \gamma_{3 c}\right]^{T}, \\
& \boldsymbol{\Lambda}_{\theta}=\left[a_{0 \theta} \gamma_{1 \theta} \gamma_{2 \theta} \gamma_{3 \theta}\right]^{T},
\end{aligned}
$$

the tunable parameters of ADRC-PDTSFC2 control law are grouped in the matrices:

$$
\begin{aligned}
& \boldsymbol{\Lambda}_{c}=\left[K_{1 c} K_{2 c} a_{0 c} \gamma_{1 c} \gamma_{2 c} \gamma_{3 c}\right]^{T}, \\
& \boldsymbol{\Lambda}_{\theta}=\left[K_{1 \theta} K_{2 \theta} a_{0 \theta} \gamma_{1 \theta} \gamma_{2 \theta} \gamma_{3 \theta}\right]^{T},
\end{aligned}
$$

$J_{e, u}$ is the objective function, the sampling time is $T_{s}=0.01 \mathrm{~s}$, the duration of an experiment is set to $79 \mathrm{~s}, N=7900$ is the number of samples and it is the result of the division between the duration of the experiment and the sampling time, the control errors are the same with the ones illustrated in Figure 6, and $\lambda$ is a penalty factor applied to the control law in order to reduce the energy consumption. The membership function parameters $B_{\hat{e} c}, B_{\Delta \hat{e} c}, B_{\hat{e} \theta}, B_{\Delta \hat{e} \theta}$ related to ADRC-PDTSFC1 and ADRC-PDTSFC2 control laws are set by the designer such that all fuzzy rules are fired during the dynamic regime in all experiments conducted on TCS; this will contribute to the improvement of CS tracking performance. The energy consumption alleviation aspect is studied through three case studies, where the penalty parameter $\lambda$ is set to $0.1,0.01$ and 0.001 in the first, second and third case study, respectively. The experiments in the three case studies are conducted using the same reference trajectory $\left[y_{c}^{*} y_{\theta}^{*}\right]^{T}$ :

$$
\begin{aligned}
& y_{c}^{*}(k)=\left\{\begin{array}{l}
0.07 \text { if } k=(1 \ldots 10) / T_{s}, 0.14 \text { if } k=(10 \ldots 20) / T_{s}, 0.07 \text { if } k=(20 \ldots 30) / T_{s}, \\
0 \text { if } k=(30 \ldots 40) / T_{s},-0.07 \text { if } k=(40 \ldots 50) / T_{s},-0.14 \text { if } k=(50 \ldots 60) / T_{s}, \\
-0.07 \text { if } k=(60 \ldots 70) / T_{s}, 0 \text { if } k=(70 \ldots 79) / T_{s},
\end{array}\right. \\
& y_{\theta}^{*}(k)=\left\{\begin{array}{l}
-0.07 \text { if } k=(1 \ldots 10) / T_{s},-0.14 \text { if } k=(10 \ldots 20) / T_{s},-0.07 \text { if } k=(20 \ldots 30) / T_{s}, \\
0 \text { if } k=(30 \ldots 40) / T_{s}, 0.07 \text { if } k=(40 \ldots 50) / T_{s}, 0.14 \text { if } k=(50 \ldots 60) / T_{s}, \\
0.07 \text { if } k=(60 \ldots 70) / T_{s}, 0 \text { if } k=(70 \ldots 79) / T_{s} .
\end{array}\right.
\end{aligned}
$$


In order to determine the parameters of ELSO for both cart position control and arm angular position control by ADRC, ADRC-PDTSFC1 and ADRC-PDTSFC2 controllers, two up-chirp signals, one for each control signal, are applied to TCS in an open-loop experiment in order to determine whether ELSO outputs track the controlled outputs $y_{c}(k)$ and $y_{\theta}(k)$. The parameters of ELSO, namely gains $l_{1}, l_{2}, l_{3}$, are obtained by arbitrarily choosing a set of eigenvalues of $(\mathbf{A}-\mathbf{L C})$ in the half plane (to ensure the ELSO stability), after validating the ELSO modeled in (8) on the TCS equipment in the dynamic regime characterized by chirp control signals and setting the initial state vector of the ELSO to $[0.4500]$. We chose the eigenvalues $\{-0.11,-0.24,-0.69\}$ for cart position and $\{-0.2,-0.17,-0.75\}$ for arm angular position, and the following ELSO gains were obtained:

$$
\begin{aligned}
& \mathbf{L}_{c}=\left[l_{1 c} l_{2 c} l_{3 c}\right]^{T}=[1.04000 .26790 .0182]^{T}, \\
& \mathbf{L}_{\theta}=\left[l_{1 \theta} l_{2 \theta} l_{3 \theta}\right]^{T}=[1.12000 .31150 .0255]^{T} .
\end{aligned}
$$

A GWO algorithm with several details, including parameterization and vector operations given [58-60], is applied to solve the optimization problem in (16) using the nonlinear mathematical model of TCS in (15) and the dynamic regime characterized by the reference trajectory in (20), zero initial conditions and no additional disturbances, which is kept in all experiments in order to evaluate the objective function values. A specific feature of GWO algorithms is:

$$
J\left(\Lambda^{\mathrm{A}_{G W O}}(\varpi)\right)<J\left(\boldsymbol{\Lambda}^{\mathrm{B}_{G W O}}(\varpi)\right)<J\left(\boldsymbol{\Lambda}^{\Gamma_{G W O}}(\varpi)\right),
$$

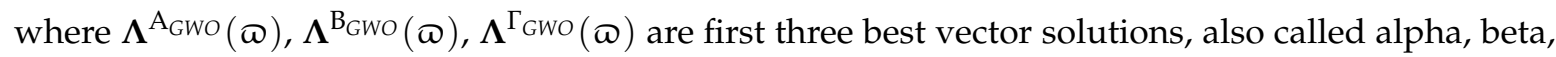
and delta, obtained after an iteration of GWO algorithm, $\varpi$ is the iteration index, and $\varpi_{\max }$ is the maximum number of iterations. The updated vector solution is:

$$
\boldsymbol{\Lambda}_{i}(\varpi+1)=\left[\boldsymbol{\Lambda}^{\mathrm{A}_{G W O}}(\varpi+1)+\boldsymbol{\Lambda}^{\mathrm{B}_{G W O}}(\varpi+1)+\Lambda^{\Gamma_{G W O}}(\varpi+1)\right] / 3, i=1 \ldots N_{G W O},
$$

where $i$ is the index of the current agent, namely the grey wolf, and the total number of agents is $N_{G W O}$.

The GWO algorithm is mapped onto the optimization problem defined in (16) in terms of:

$$
\begin{aligned}
& \boldsymbol{\Lambda}_{i}(\varpi)=\boldsymbol{\Lambda}, i=1 \ldots N_{G W O}, \\
& \boldsymbol{\Lambda}_{i}\left(\varpi_{\max }\right)=\boldsymbol{\Lambda}^{*} .
\end{aligned}
$$

The parameters of the GWO algorithm that solves the optimization problem defined in (16) are $N_{G W O}=20$ and $\varpi_{\max }=100$. They were chosen such that to reach an acceptable tradeoff to converge and computational resources. The search domains for all parameters of ADRC, ADRC-PDTSFC1 and ADRC-PDTSFC2 controllers was set to the interval [-100, 100].

The first case study is characterized by setting the penalty factor to $\lambda=0.1$. The GWO-based solving of the optimization problem in (16) leads to the following values of controller parameters:

$$
\begin{aligned}
& \Lambda_{c}^{*}=[26.0406-0.2468-15.4261]^{T}, \\
& \Lambda_{\theta}^{*}=[6.3330-0.72800 .8244]^{T},
\end{aligned}
$$

for the CS with ADRC controller,

$$
\begin{aligned}
& \Lambda_{c}^{*}=[-15.42610 .72000 .80001]^{T}, \\
& \Lambda_{\theta}^{*}=[0.82440 .76500 .79901]^{T},
\end{aligned}
$$


and the membership function parameters set to $B_{\hat{e} c}=0.1400, B_{\Delta \hat{e} c}=3.6937, B_{\hat{e} \theta}=0.1401, B_{\Delta \hat{e} \theta}=0.3045$ for the CS with ADRC-PDTSFC1 controller,

$$
\begin{aligned}
& \Lambda_{c}^{*}=[26.0406-0.2468-15.42610 .71190 .80151]^{T}, \\
& \Lambda_{\theta}^{*}=[6.3330-0.72800 .82440 .76400 .80101]^{T},
\end{aligned}
$$

and the membership function parameters set to $B_{\hat{e} c}=0.1400, B_{\Delta \hat{e} c}=3.6616, B_{\hat{e} \theta}=0.1401, B_{\Delta \hat{e} \theta}=0.0196$ for the CS with ADRC-PDTSFC2 controller.

The experimental results for the three control systems are presented in Figure 7 in terms of the following plots: in Figure 7a) the control signal $u_{c}$ for ADRC is with red line, $u_{c}$ for ADRC-PDTSFC1 is with blue line and $u_{c}$ for ADRC-PDTSFC2 is with green line; in Figure $7 \mathrm{~b}$ ) the reference trajectory $y_{c}^{*}$ is with thick black dashed line, the controlled output $y_{c}$ for ADRC is with red line, $y_{c}$ for ADRC-PDTSFC1 is with blue line and $y_{c}$ for ADRC-PDTSFC2 is with green line; in Figure 7c) the control signal $u_{\theta}$ for ADRC is with red line, $u_{\theta}$ for ADRC-PDTSFC1 is with blue line and $u_{\theta}$ for ADRC-PDTSFC2 is with green line; in Figure $7 \mathrm{~d}$ ) the reference trajectory $y_{\theta}^{*}$ is with thick black dashed line, the controlled output $y_{\theta}$ for ADRC is with red line, $y_{\theta}$ for ADRC-PDTSFC1 is with blue line and $y_{\theta}$ for ADRC-PDTSFC2 is with green line.

In order to have a fair comparison between the obtained results of the CSs with ADRC, ADRC-PDTSFC1 and ADRC-PDTSFC2 controllers, and to mitigate the effects of random disturbances that occur unexpectedly during the experiments, the graphical results presented in Figure 7 were averaged ten times.
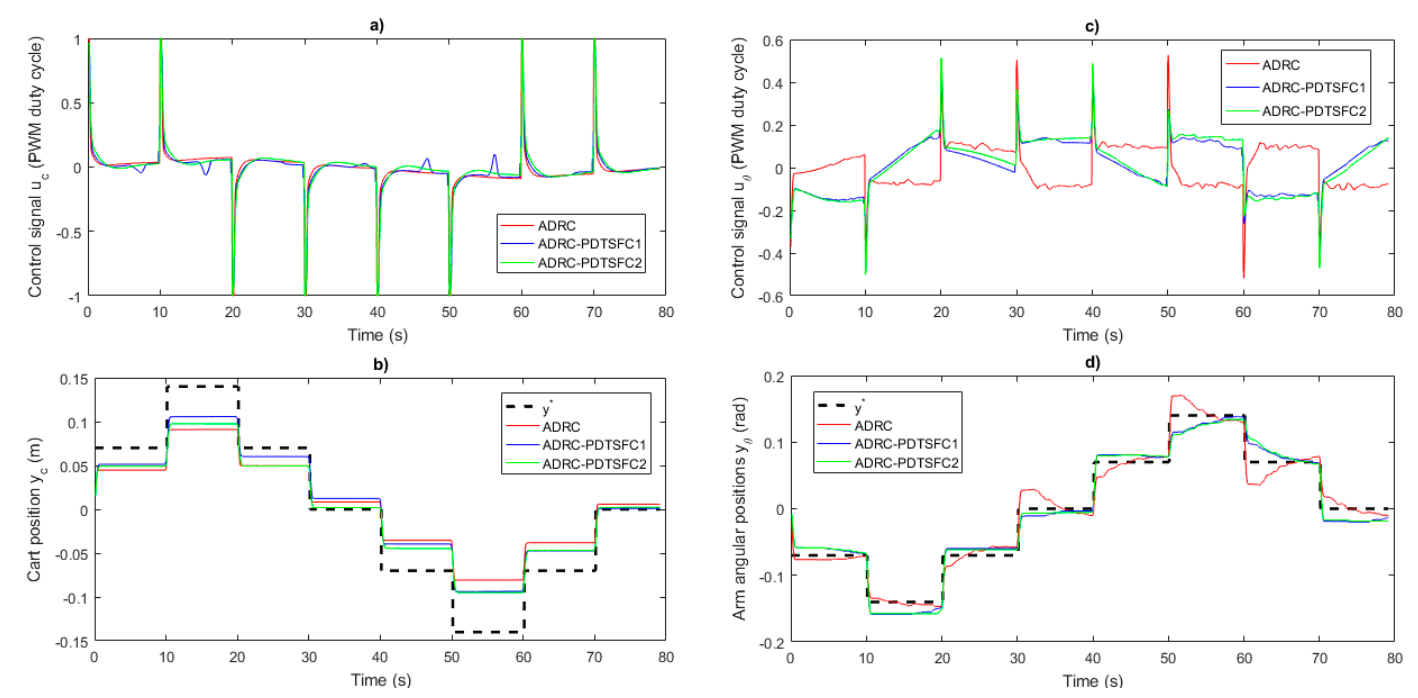

Figure 7. Experimental results in the first case study for control systems (CSs) with ADRC, ADRC-PDTSFC1 and ADRC-PDTSFC2 controllers.

The obtained results representing the average and the variance of the objective functions $J_{e, u}$ of CSs with ADRC, ADRC-PDTSFC1 and ADRC-PDTSFC2 controllers are presented in Table 2.

Table 2. The measured objective functions for the CS with ADRC, ADRC-PDTSFC1 and ADRC-PDTSFC2 controllers.

\begin{tabular}{cccc}
\hline $\begin{array}{c}\text { 1st Case Study } \\
(\boldsymbol{\lambda}=\mathbf{0 . 1})\end{array}$ & ADRC & ADRC-PDTSFC1 & ADRC-PDTSFC2 \\
\hline Average of $J_{e, u}$ & 0.0071 & 0.0063 & 0.0063 \\
Variance of $J_{e, u}$ & $5.2829 \times 10^{-8}$ & $1.4702 \times 10^{-7}$ & $1.9381 \times 10^{-8}$ \\
\hline
\end{tabular}

Analysis of the results given in Figure 7 and Table 2 leads to the conclusion that the CSs with ADRC-PDTSFC1 and ADRC-PDTSFC2 controllers have performance in the same range and both 
outperform the CS with ADRC controller. The following relationships between the average values of the objective functions of the three CSs are expressed: $J_{e, u A D R C} \cong 1.127 J_{e, u A D R C-P D T S F C 1}$ and $J_{e, u} A D R C \cong 1.127 J_{e, u A D R C-P D T S F C 2}$. In this regard, considering the variance of the objective functions, the ranking of the objective functions in Table 2 is $J_{e, u} A D R C-P D T S F C 2<J_{e, u} A D R C-P D T S F C 1<J_{e, u} A D R C$.

The second case is characterized by modifying the penalty factor to $\lambda=0.01$. After executing the GWO in order to solve the optimization problem in (16), the following values of controller parameters were obtained:

$$
\begin{aligned}
& \boldsymbol{\Lambda}_{c}^{*}=[52.7304-0.8945-1.0450]^{T}, \\
& \Lambda_{\theta}^{*}=[15.8098-0.40860 .7710]^{T},
\end{aligned}
$$

for the CS with ADRC controller,

$$
\begin{aligned}
& \Lambda_{c}^{*}=[-1.04500 .73010 .80091]^{T}, \\
& \Lambda_{\theta}^{*}=[0.77100 .76550 .80011]^{T},
\end{aligned}
$$

and the membership function parameters set to $B_{\hat{e} c}=0.1400, B_{\Delta \hat{e} c}=2.632, B_{\hat{e} \theta}=0.1400, B_{\Delta \hat{e} \theta}=1.3542$ for the CS with ADRC-PDTSFC1 controller,

$$
\begin{aligned}
& \Lambda_{c}^{*}=[52.7304-0.8945-1.04500 .71150 .80031]^{T}, \\
& \Lambda_{\theta}^{*}=[15.8098-0.40860 .77100 .76380 .80051]^{T},
\end{aligned}
$$

and the membership function parameters set to $B_{\hat{e} c}=0.1400, B_{\Delta \hat{e} c}=3.1161, B_{\hat{e} \theta}=0.1400, B_{\Delta \hat{e} \theta}=0.0123$ for the CS with ADRC-PDTSFC2 controller.

As in the previous case study, the experimental results for the control systems, namely ADRC, ADRC-PDTSFC1 and ADRC-PDTSFC2, are presented in Figure 8 in terms of the following plots: in Figure $8 \mathrm{a}$ ) the control signal $u_{c}$ for ADRC is with red line, $u_{c}$ for ADRC-PDTSFC 1 is with blue line and $u_{c}$ for ADRC-PDTSFC2 is with green line; in Figure $8 b$ ) the reference trajectory $y_{c}^{*}$ is with thick black dashed line, the controlled output $y_{c}$ for ADRC is with red line, $y_{c}$ for ADRC-PDTSFC1 is with blue line and $y_{c}$ for ADRC-PDTSFC2 is with green line; in Figure 8c) the control signal $u_{\theta}$ for ADRC is with red line, $u_{\theta}$ for ADRC-PDTSFC1 is with blue line and $u_{\theta}$ for ADRC-PDTSFC2 is with green line; in Figure $8 \mathrm{~d}$ ) the reference trajectory $y_{\theta}^{*}$ is with thick black dashed line, the controlled output $y_{\theta}$ for ADRC is with red line, $y_{\theta}$ for ADRC-PDTSFC1 is with blue line and $y_{\theta}$ for ADRC-PDTSFC2 is with green line.
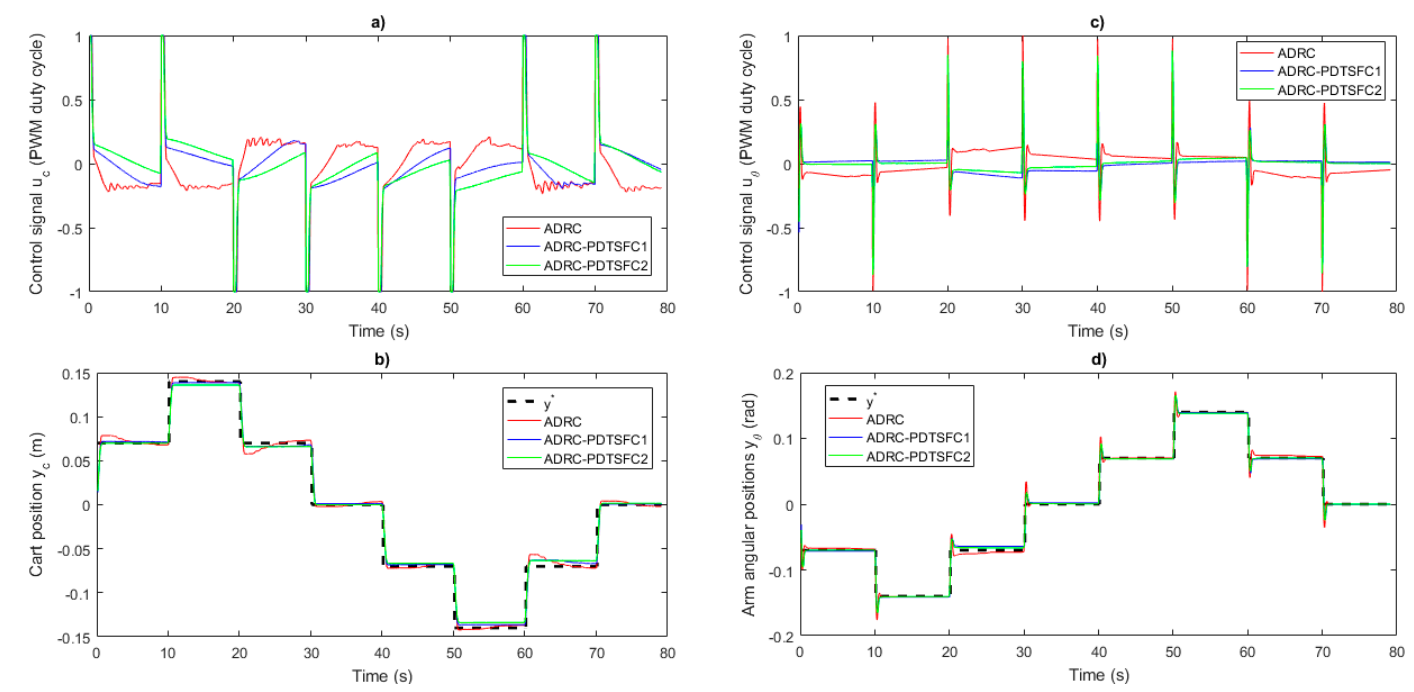

Figure 8. Experimental results in the second case study for CSs with ADRC, ADRC-PDTSFC1 and ADRC-PDTSFC2 controllers. 
In order to have a fair comparison between the results obtained of the CSs with ADRC, ADRC-PDTSFC1 and ADRC-PDTSFC2 controllers, and to mitigate the effects of random disturbances that occur unexpectedly during the experiments, the graphical results presented in Figure 8 were averaged ten times to eliminate this type of disturbance.

The results obtained that represent the average and the variance of the objective functions $J_{e, u}$ of CS with ADRC, ADRC-PDTSFC1 and ADRC-PDTSFC2 controllers are presented in Table 3.

Table 3. The measured objective functions for the CS with ADRC, ADRC-PDTSFC1 and ADRC-PDTSFC2 controllers.

\begin{tabular}{cccc}
\hline $\begin{array}{c}\text { 1st Case Study } \\
(\boldsymbol{\lambda}=\mathbf{0 . 0 1})\end{array}$ & ADRC & ADRC-PDTSFC1 & ADRC-PDTSFC2 \\
\hline Average of $J_{e, u}$ & 0.0012 & $8.6663 \times 10^{-4}$ & $8.3532 \times 10^{-4}$ \\
Variance of $J_{e, u}$ & $3.6726 \times 10^{-10}$ & $7.1329 \times 10^{-11}$ & $1.3778 \times 10^{-8}$ \\
\hline
\end{tabular}

As in the first case study, the analysis of the results given in Figure 8 and Table 3 leads to the conclusion that the CSs with ADRC-PDTSFC1 and ADRC-PDTSFC2 controllers have similar performances and they overperform the CS with ADRC controller. The following relationships between the average values of the objective functions of the three CSs are expressed: $J_{e, u A D R C} \cong 1.385 J_{e, u A D R C-P D T S F C 1}$ and $J_{e, u A D R C} \cong 1.437_{e, u A D R C-P D T S F C 2}$. Considering the variance of the objective functions, the ranking of the objective functions in Table 3 is $J_{e, u}$ ADRC-PDTSFC2 $<J_{e, u A D R C-P D T S F C 1}<J_{e, u A D R C}$.

The third case study is characterized by setting the penalty factor this time to $\lambda=0.001$. The optimization problem in (16) is solved using GWO leading to the following values of controller parameters:

$$
\begin{aligned}
& \Lambda_{c}^{*}=[49.5488-1.36540 .8411]^{T}, \\
& \Lambda_{\theta}^{*}=[16.8571-0.48381 .0841]^{T},
\end{aligned}
$$

for the CS with ADRC controller,

$$
\begin{aligned}
& \Lambda_{c}^{*}=[0.84110 .72020 .79991]^{T}, \\
& \Lambda_{\theta}^{*}=[1.08410 .76510 .80001]^{T},
\end{aligned}
$$

and the membership function parameters set to $B_{\hat{e} c}=0.1400, B_{\Delta \hat{e} c}=1.2701, B_{\hat{e} \theta}=0.1400, B_{\Delta \hat{e} \theta}=1.2196$ for the CS with ADRC-PDTSFC1 controller,

$$
\begin{aligned}
& \Lambda_{c}^{*}=[49.5488-1.36540 .84110 .71230 .80321]^{T}, \\
& \Lambda_{\theta}^{*}=[16.8571-0.48381 .08410 .76350 .80111]^{T},
\end{aligned}
$$

and the membership function parameters set to $B_{\hat{e} c}=0.1400, B_{\Delta \hat{e} c}=3.2774, B_{\hat{e} \theta}=0.1400, B_{\Delta \hat{e} \theta}=0.0240$ for the CS with ADRC-PDTSFC2 controller.

As in the case studies above, the experimental results for the CSs with ADRC-PDTSFC1 and ADRC-PDTSFC 2 controllers are presented in Figure 9 in terms of the following plots: in Figure 9a) the control signal $u_{c}$ for ADRC is with red line, $u_{c}$ for ADRC-PDTSFC1 is with blue line and $u_{c}$ for ADRC-PDTSFC2 is with green line; in Figure $9 \mathrm{~b}$ ) the reference trajectory $y_{c}^{*}$ is with thick black dashed line, the controlled output $y_{c}$ for ADRC is with red line, $y_{c}$ for ADRC-PDTSFC1 is with blue line and $y_{c}$ for ADRC-PDTSFC2 is with green line; in Figure 9c) the control signal $u_{\theta}$ for ADRC is with red line, $u_{\theta}$ for ADRC-PDTSFC1 is with blue line and $u_{\theta}$ for ADRC-PDTSFC2 is with green line; in Figure 9d) the reference trajectory $y_{\theta}^{*}$ is with thick black dashed line, the controlled output $y_{\theta}$ for ADRC is with red line, $y_{\theta}$ for ADRC-PDTSFC1 is with blue line and $y_{\theta}$ for ADRC-PDTSFC2 is with green line.

To have a fair comparison between the obtained results of the CSs with ADRC, ADRC-PDTSFC1 and ADRC-PDTSFC2 controller, and mitigate the effects of random disturbances that occur 
unexpectedly during the experiments, the graphical results presented in Figure 9 were averaged ten times.
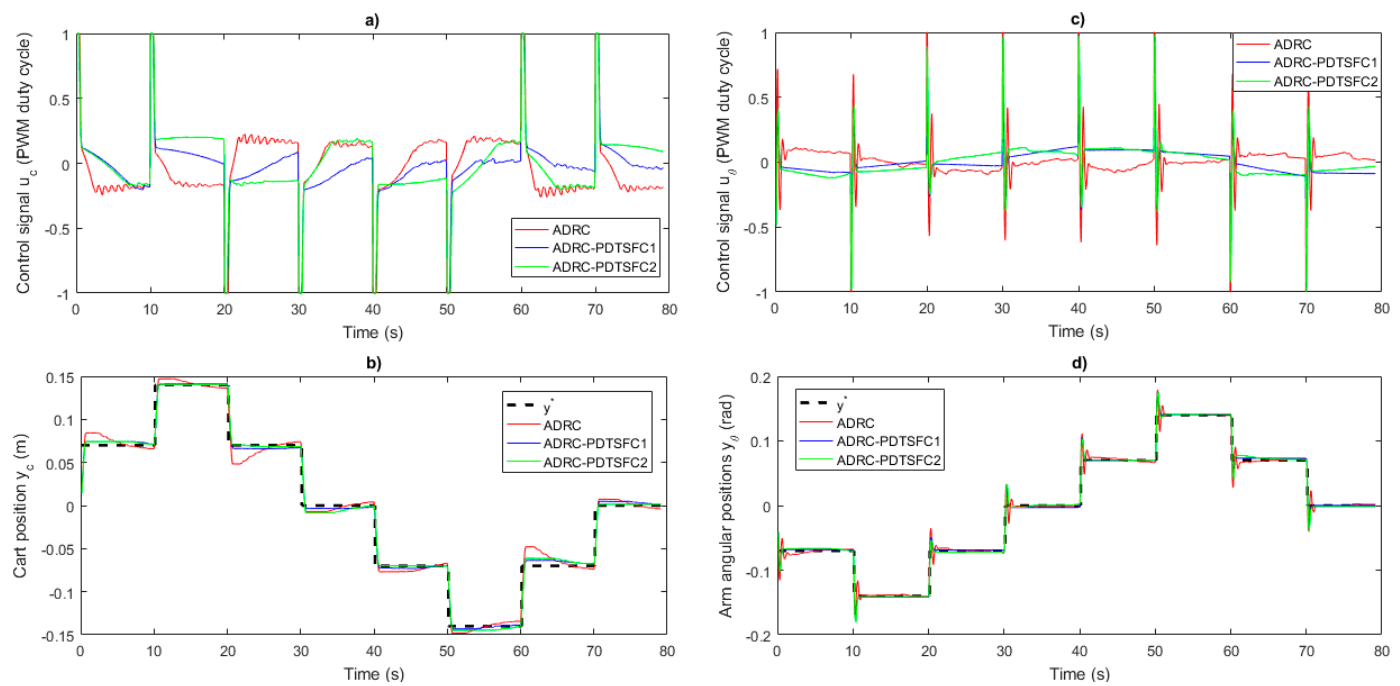

Figure 9. Experimental results in the third case study for CSs with ADRC, ADRC-PDTSFC1 and ADRC-PDTSFC2 controllers.

Using the same presentation style in the first two case studies, the results obtained in the third case study representing the average and the variance of the objective functions $J_{e, u}$ of the CSs with ADRC, ADRC-PDTSFC1 and ADRC-PDTSFC2 controllers are presented in Table 4.

Table 4. The measured objective functions for the CS with ADRC, ADRC-PDTSFC1 and ADRC-PDTSFC2 controllers.

\begin{tabular}{cccc}
\hline $\begin{array}{c}\text { 1st Case Study } \\
(\boldsymbol{\lambda}=\mathbf{0 . 0 0 1})\end{array}$ & ADRC & ADRC-PDTSFC1 & ADRC-PDTSFC2 \\
\hline Average of $J_{e, u}$ & $3.8769 \times 10^{-4}$ & $2.8189 \times 10^{-4}$ & $2.9013 \times 10^{-4}$ \\
Variance of $J_{e, u}$ & $9.2359 \times 10^{-11}$ & $2.5149 \times 10^{-11}$ & $3.6931 \times 10^{-11}$ \\
\hline
\end{tabular}

As in the previous case studies, the analysis of the results given in Figure 9 and Table 4 allows for the conclusion that the CSs with ADRC-PDTSFC1 and ADRC-PDTSFC2 controllers have similar performances, and both perform better than the CS with ADRC controller. The following relationships between the average values of the CSs with ADRC-PDTSFC1 and ADRC-PDTSFC2 controllers are expressed: $J_{e, u A D R C} \cong 1.375 J_{e, u A D R C-P D T S F C 1}$ and $J_{e, u A D R C} \cong 1.336 J_{e, u A D R C-P D T S F C 2}$. Considering the above, the variance and the ranking of the objective functions in Table 4 is $J_{e, u}$ ADRC-PDTSFC1 $<$ $J_{e, u} A D R C-P D T S F C 2<J_{e, u} A D R C$.

\section{Conclusions}

Using data-driven control as a starting point, this paper proposed a fusion of control methods which are meant to improve energy consumption for a TCS, resulting in three data-driven controllers, namely ADRC, ADRC-PDTSFC1 and ADRC-PDTSFC2. The new ADRC-PDTSFC structures improve the overall CS performance by compensating for shortcomings of ADRC. The data-driven controllers were validated through real-time experiments to control the cart position and the arm angular position of the MIMO nonlinear TCS laboratory equipment. The data-driven controllers were implemented as two independent SISO control system structures that are running in parallel.

This paper also suggested the improvement of the energy consumption for TCS, therefore penalty factor $\lambda$ was inserted in the proposed objective function in (16) in order to reduce the energy consumption. 
Three case studies with three values of the penalty factor $\lambda$ were defined discussed in order to determine how the energy consumption influences the output tracking performance of TCS. Considering the experimental results given in Section 5 and illustrated in Figures 6-8 and Tables 2-4, the conclusion is that if the practitioner wants to minimize the energy consumption, a large value of the penalty factor should be used, but this can seriously affect the tracking performance defined in cart and arm angular positions. If the penalty factor in the objective function is set to a small value, the energy consumption will increase, but also the CS tracking performance will be improved. Therefore, the practitioner must achieve a compromise to energy consumption and output tracking performance of TCS.

The main advantage of the proposed ADRC-PDTSFC structures in comparison with the ADRC structure is that both ADRC-PDTSFC1 and ADRC-PDTSFC2 improve the overall tracking performances of the TCS for any penalty parameter $\lambda$ used in the objective function. In the first case study the ADRC-PDTSFC1 and ADRC-PDTSFC2 controllers are 1.375 times better than the ADRC controller as far as the average value of the minimum objective function is concerned. In the second case study the ADRC-PDTSFC1 is 1.385 times better than the ADRC controller and the ADRC-PDTSFC2 controller is 1.437 times better than the ADRC controller. And in the third case study the ADRC-PDTSFC1 is 1.375 times better than the ADRC controller and the ADRC-PDTSFC2 controller is 1.336 times better than the ADRC controller. In all three case studies the CSs with ADRC-PDTSFC exhibit improved performance over the CS with ADRC controller.

The main shortcoming of the proposed ADRC-PDTSFC structures is that the number of parameters is higher compared to the initial ADRC structure. The ADRC controller applied to a SISO process has 5 parameters. The ADRC-PDTSFC1 controller applied to a SISO process has 10 parameters, that is, 5 parameters of the ADRC controller plus 3 parameters of the rule base of the fuzzy component plus 2 parameters of the input membership functions. The ADRC-PDTSFC2 controller applied to a SISO process has 12 parameters, namely 5 parameters of the ADRC controller plus 5 parameters of the rule base of the fuzzy component including the PD component plus 2 parameters of the input membership functions.

Future work will be focused on the combination of different data-driven techniques with other fuzzy logic techniques [61-67] targeting experimental validation on different nonlinear laboratory equipment and real-world applications including large-scale systems [61], robotics and autonomous systems [68-72], medicine [73-75], engines [76] and combining with fault diagnosis and optimization [77-82].

Author Contributions: R.-C.R. wrote the paper, performed the experiments, analyzed the algorithms and prepared the theoretical results in Section 5; R.-E.P. revised the mathematical formulations, implemented the GWO algorithm and ensured the hardware and software support; E.M.P. revised the paper and ensured the systematic comparison and validation; F.D. provided the hardware support and performed the experiments. All authors have read and approved the final paper.

Funding: This research was funded by Politehnica University of Timisoara, grant GNaC2018-ARUT, no. 1348/01.02.2019, and the NSERC of Canada.

Acknowledgments: This work was supported in part by the research grant GNaC2018 —ARUT, no. 1348/01.02.2019, financed by Politehnica University of Timisoara, and by the NSERC of Canada.

Conflicts of Interest: The authors declare no conflict of interest.

\section{References}

1. Gao, Z. Active disturbance rejection control: A paradigm shift in feedback control system design. In Proceedings of the 2006 American Control Conference, Minneapolis, MN, USA, 14-16 June 2006; pp. 2399-2405.

2. Herbst, G. A simulative study on Active Disturbance Rejection Control (ADRC) as a control tool for practitioners. Electronics 2013, 2, 246-279. [CrossRef]

3. Han, J. From PID to active disturbance rejection control. IEEE Trans. Ind. Electron. 2009, 56, 900-906. [CrossRef] 
4. He, T.; Wu, Z.; Shi, R.; Li, D.; Sun, L.; Wang, L.; Zheng, S. Maximum sensitivity-constrained data-driven active disturbance rejection control with application to airflow control in power plant. Energies 2019, 12, 231. [CrossRef]

5. Hou, Z.S.; Zhu, Y.M. Controller-dynamic-linearization-based model free adaptive control for discrete-time nonlinear systems. IEEE Trans. Ind. Inform. 2013, 9, 2301-2309. [CrossRef]

6. Hou, Z.S.; Jin, S. A novel data-driven control approach for a class of discrete-time nonlinear systems. IEEE Trans. Control Syst. Technol. 2011, 19, 1549-1558. [CrossRef]

7. Roman, R.-C.; Radac, M.-B.; Precup, R.-E.; Petriu, E.M. Data-driven model-free adaptive control tuned by virtual reference feedback tuning. Acta Polytech. Hung. 2016, 13, 83-96.

8. Hou, Z.S.; Xiong, S. On model-free adaptive control and its stability analysis. IEEE Trans. Autom. Control 2019. [CrossRef]

9. Roman, R.-C.; Radac, M.-B.; Precup, R.-E. Multi-input-multi-output system experimental validation of model-free control and virtual reference feedback tuning techniques. IET Control Theory Appl. 2016, 10, 1395-1403. [CrossRef]

10. Abouaïssa, H.; Fliess, M.; Join, C. On ramp metering: Towards a better understanding of ALINEA via model-free control. Int. J. Control 2017, 90, 1018-1026. [CrossRef]

11. Roman, R.-C.; Radac, M.-B.; Precup, R.-E.; Petriu, E.M. Virtual reference feedback tuning of model-free control algorithms for servo systems. Machines 2017, 5, 25. [CrossRef]

12. Menhour, L.; d'Andréa-Novel, B.; Fliess, M.; Gruyer, D.; Mounier, H. An efficient model-free setting for longitudinal and lateral vehicle control: Validation through the interconnected Pro-SiVIC/RTMaps prototyping platform. IEEE Trans. Intell. Transp. Syst. 2018, 19, 461-475. [CrossRef]

13. Bara, O.; Fliess, M.; Join, C.; Day, J.; Djouadi, S.M. Toward a model-free feedback control synthesis for treating acute inflammation. J. Theor. Biol. 2018, 448, 26-37. [CrossRef] [PubMed]

14. Precup, R.-E.; Radac, M.-B.; Roman, R.-C.; Petriu, E.M. Model-free sliding mode control of nonlinear systems: Algorithms and experiments. Informing Sci. 2017, 381, 176-192. [CrossRef]

15. Campi, M.C.; Lecchini, A.; Savaresi, S.M. Virtual reference feedback tuning: A direct method for the design of feedback controllers. Automatica 2002, 38, 1337-1346. [CrossRef]

16. Campestrini, L.; Eckhard, D.; Chía, L.A.; Boeira, E. Unbiased MIMO VRFT with application to process control. J. Proc. Control 2016, 39, 35-49. [CrossRef]

17. Roman, R.-C.; Radac, M.-B.; Precup, R.-E. Mixed MFC-VRFT approach for multivariable aerodynamic system position control. In Proceedings of the 2016 IEEE International Conference on Systems, Man, and Cybernetics, Budapest, Hungary, 9-12 October 2016; pp. 2615-2620.

18. Invernizzi, D.; Panizza, P.; Riccardi, F.; Formentin, S.; Lovera, M. Data-driven attitude control law of a variable-pitch quadrotor: A comparison study. IFAC-PapersOnLine 2016, 49, 236-241. [CrossRef]

19. You, J.; Fan, W.; Yu, L.; Fu, B.; Liao, M. Disturbance rejection control method of double-switch buck-boost converter using combined control strategy. Energies 2019, 12, 278. [CrossRef]

20. Qi, X.; Bai, Y. Improved linear active disturbance rejection control for microgrid frequency regulation. Energies 2017, 10, 1047. [CrossRef]

21. Roman, R.-C.; Radac, M.-B.; Tureac, C.; Precup, R.-E. Data-driven active disturbance rejection control of pendulum cart systems. In Proceedings of the 2018 IEEE Conference on Control Technology and Applications, Copenhagen, Denmark, 21-24 August 2018; pp. 933-938.

22. Li, M.; Li, D.; Wang, J.; Zhao, C. Active disturbance rejection control for fractional-order system. ISA Trans. 2013, 52, 365-374. [CrossRef]

23. Zhang, G.; Wang, G.; Yuan, B.; Liu, R.; Xu, D. Active disturbance rejection control strategy for signal injection based sensorless IPMSM drivers. IEEE Trans. Transp. Electr. 2018, 4, 330-339. [CrossRef]

24. Shi, D.; Xue, J.; Zhao, L.; Wang, J.; Huang, Y. Event-triggered active disturbance rejection control of DC torque motors. IEEE/ASME Trans. Mechatron. 2017, 22, 2277-2287. [CrossRef]

25. Alonge, F.; Cirrincione, M.; D'Ippolito, F.; Pucci, M.; Sferlazza, A. Active disturbance rejection control for linear induction motor. IEEE Trans. Ind. Appl. 2017, 53, 4460-4471. [CrossRef]

26. Jiang, Y.; Sun, Q.; Zhang, X.; Chen, Z. Pressure regulation for oxygen mask based on active disturbance rejection control. IEEE Trans. Ind. Electron. 2017, 64, 6402-6411. [CrossRef]

27. Yao, J.; Deng, W. Active disturbance rejection control of hydraulic servo systems. IEEE Trans. Ind. Electron. 2017, 64, 8023-8032. [CrossRef] 
28. Zhang, B.; Tan, W.; Li, J. Tuning of linear active disturbance rejection controller with robustness specification. ISA Trans. 2019, 85, 237-246. [CrossRef]

29. Karkoub, M.; Wu, T.-S.; Chen, C.-T. $\mathrm{H}_{\infty}$ based adaptive fuzzy control of a tower crane system. In Proceedings of the ASME 2012 International Mechanical Engineering Congress \& Exposition, Huston, TX, SUA, 9-15 November 2015; pp. 1-6.

30. Wu, T.-S.; Karkoub, M.; Yu, W.-S.; Chen, C.-T.; Her, M.-G.; Wu, K.-W. Anti-sway tracking control of tower cranes with delayed uncertainty using arobust adaptive fuzzy control. Fuzzy Sets Syst. 2016, 290, 118-137. [CrossRef]

31. Omar, H.M.; Nayfeh, A.H. Anti-swing control of gantry and tower cranes using fuzzy and time-delayed feedback with friction compensation. Shock Vib. 2005, 12, 73-89. [CrossRef]

32. Sadati, N.; Hooshmand, A. Design of a gain-scheduling anti-swing controller for tower cranes using fuzzy clustering techniques. In Proceedings of the 2006 International Conference on Computational Intelligence for Modelling Control and Automation and International Conference on Intelligent Agents Web Technologies and International Commerce, Sydney, NSW, Australia, 28 November-1 December 2006; pp. 1-6.

33. Hanna, A.S.; Lotfallah, W.B. Fuzzy logic approach to the selection of cranes. Autom. Constr. 1999, 8, 597-608. [CrossRef]

34. Liang, Y.C.; Koh, K.K. Concise anti-swing approach for fuzzy crane control. Electron. Lett. 1997, 33, 167-168. [CrossRef]

35. Smoczek, J. Fuzzy crane control with sensorless payload deflection feedback for vibration reduction. Mech. Syst. Signal Proc. 2014, 46, 70-81. [CrossRef]

36. Al-Mousa, A.A.; Nayfeh, A.H.; Kachroo, P. Control of rotary cranes using fuzzy logic. Shock Vib. 2005, 10, 81-95. [CrossRef]

37. Dong, Q.; Li, Q. Current control of BLDCM based on fuzzy adaptive ADRC. In Proceedings of the 2009 Ninth International Conference on Hybrid Intelligent Systems, Shenyang, China, 12-14 August 2009; pp. 355-358.

38. Zhou, Y.; Pan, W.; Xiao, H. Design of ship course controller based on fuzzy adaptive active disturbance rejection technique. In Proceedings of the 2010 IEEE International Conference on Automation and Logistics, Hong Kong and Macau, China, 16-20 August 2010; pp. 232-236.

39. Su, G. Fuzzy ADRC controller design for PMSM speed regulation system. Adv. Mater. Res. 2011, 201-203, 2405-2408. [CrossRef]

40. Huang, S.; Kuang, J.; Huang, Q.; Huang, K.; Gao, J.; Liu, T. IPMSM sensorless control based on fuzzy active-disturbance rejection controller for electric vehicle. In Proceedings of the 2011 International Conference on Power Engineering, Energy and Electrical Drives, Torremolinos (Malaga), Spain, 11-13 May 2011; pp. 1-6.

41. Zhu, Y.; Fan, G.; Yi, J. Controller design based on T-S fuzzy reasoning and ADRC for a flying boat. In Proceedings of the 10th IEEE International Conference on Control and Automation, Hangzhou, China, 12-14 June 2013; pp. 1578-1583.

42. Gai, J.-T.; Huang, S.-D.; Huang, Q.; Li, M.-Q.; Wang, H.; Luo, D.-R.; Wu, X.; Lio, W. A new fuzzy active-disturbance rejection controller applied in PMSM position servo system. In Proceedings of the 17th International Conference on Electrical Machines and Systems, Hangzhou, China, 22-25 October 2014; pp. 2055-2059.

43. Hui, L.; Zingqiao, L.; Jing, L. The research of fuzzy immune linear active disturbance rejection control strategy for three-motor synchronous system. Control Eng. Appl. Inform. 2015, 14, 50-58.

44. Zhong, C.; Guo, Y.; Wang, L. Fuzzy active disturbance rejection attitude control of spacecraft with unknown disturbance and parametric uncertainty. Int. J. Control Autom. 2015, 8, 233-242. [CrossRef]

45. Su, T.-J.; Wang, S.-M.; Tsai, J.S.-H.; Tsou, T.-Y.; Tran, V.-K. Design of fuzzy and linear active disturbance rejection control for insulin infusion in type 1 diabetic patients. Int. J. Fuzzy Syst. 2017, 19, 1966-1977. [CrossRef]

46. Yang, J.; Yang, Z.; Sun, X. Control design for nonlinear electromechanical actuation system based on fuzzy PID and active disturbance rejection control. In Proceedings of the 2018 Chinese Control and Decision Conference, Shenyang, China, 9-11 June 2018; pp. 1387-1391.

47. Matuško, J.; Ileš, Š.; Kolonic, F.; Lešic, V. Control of 3D tower crane based on tensor product model transformation with neural friction compensation. Asian J. Control 2015, 17, 443-458. [CrossRef]

48. Doung, S.C.; Uezato, E.; Kinjo, H.; Yamamoto, T. A hybrid evolutionary algorithm for recurrent neural network control of a three-dimensional tower crane. Autom. Constr. 2012, 23, 55-63. [CrossRef] 
49. Omar, H.M.; Nayfeh, A.H. Gain scheduling feedback control of tower cranes with friction compensation. J. Vib. Control 2004, 10, 269-289. [CrossRef]

50. Barisa, T.; Bartulovic, M.; Zuzic, G.; Iles, S.; Matusko, J.; Kolonic, F. Nonlinear predictive control of a tower crane using reference shaping approach. In Proceedings of the 16th International Power Electronics and Motion Control Conference and Exposition, Antalya, Turkey, 21-24 September 2014; pp. 872-876.

51. Singhose, W.; Kim, D. Manipulation with tower cranes exhibiting double-pendulum oscillations. In Proceedings of the 2007 IEEE International Conference on Robotics and Automation, Roma, Italy, 10-14 April 2007; pp. 4550-4555.

52. Sun, N.; Fang, Y.; Chen, H.; Lu, B.; Fu, Y. Slew/translation positioning and swing suppression for 4-DOF tower cranes with parametric uncertainties: Design and hardware experimentation. IEEE Trans. Ind. Electron. 2016, 63, 6407-6418. [CrossRef]

53. Sun, N.; Wu, Y.; Chen, H.; Fang, Y. Antiswing cargo transportation of underactuated tower crane systems by a nonlinear controller embedded with an integral term. IEEE Trans. Autom. Sci. Eng. 2019. [CrossRef]

54. Tinkir, M.; Kalyoncu, M.; Omen, U.; Sahin, Y. Modeling and control of scaled a tower crane system. In Proceedings of the 2011 3rd International Conference on Computer Research and Development, Shanghai, China, 11-13 March 2011; pp. 1461-1473.

55. Gao, B.; Shao, J.; Yang, X. A compound control strategy combining velocity compensation with ADRC of electro-hydraulic position servo control system. ISA Trans. 2014, 53, 1910-1918. [CrossRef]

56. Roman, R.-C.; Precup, R.-E.; Radac, M.-B. Model-free fuzzy control of twin rotor aerodynamic systems. In Proceedings of the 2017 25th Mediterranean Conference on Control ant Automation, Valletta, Malta, 3-6 July 2017; pp. 559-564.

57. Inteco Ltd. Modular Servo System, User's Manual; Inteco Ltd.: Krakow, Poland, 2006.

58. Precup, R.-E.; David, R.-C.; Petriu, E.M. Grey wolf optimizer algorithm-based tuning of fuzzy control systems with reduced parametric sensitivity. IEEE Trans Ind Electron. 2017, 64, 527-534. [CrossRef]

59. Precup, R.-E.; David, R.-C.; Szedlak-Stinean, A.-I.; Petriu, E.M.; Dragan, F. An easily understandable grey wolf optimizer and its application to fuzzy controller tuning. Algorithms 2017, 10, 68. [CrossRef]

60. Roman, R.-C.; Precup, R.-E.; David, R.-C. Second order intelligent proportional-integral fuzzy control of twin rotor aerodynamic systems. Proc. Comput. Sci. 2018, 139, 372-380. [CrossRef]

61. Haber, R.E.; Alique, J.R.; Alique, A.; Hernández, J.; Uribe-Etxebarria, R. Embedded fuzzy-control system for machining processes: Results of a case study. Comput. Ind. 2003, 50, 353-366. [CrossRef]

62. Precup, R.-E.; Tomescu, M.L.; Preitl, S.; Petriu, E.M.; Fodor, J.; Pozna, C. Stability analysis and design of a class of MIMO fuzzy control systems. J. Intell. Fuzzy Syst. 2013, 25, 145-155.

63. Haidegger, T.; Kovács, L.; Precup, R.-E.; Benyó, B.; Benyó, Z.; Preitl, S. Simulation and control for telerobots in space medicine. Acta Astron. 2012, 181, 390-402. [CrossRef]

64. Olivas, F.; Valdez, F.; Castillo, O.; González, C.I.; Martinez, G.E.; Melin, P. Ant colony optimization with dynamic parameter adaptation based on interval type-2 fuzzy logic systems. Appl. Soft Comput. 2017, 53, 74-87. [CrossRef]

65. Navarro, G.; Umberger, D.K.; Manic, M. VD-IT2, virtual disk cloning on disk arrays using a type-2 fuzzy controller. IEEE Trans. Fuzzy Syst. 2017, 25, 1752-1764. [CrossRef]

66. Johanyák, Z.C. A modified particle swarm optimization algorithm for the optimization of a fuzzy classification subsystem in a series hybrid electric vehicle. Tehnički Vjesnik 2017, 24, 295-301.

67. Vrkalovic, S.; Lunca, E.-C.; Borlea, I.-D. Model-free sliding mode and fuzzy controllers for reverse osmosis desalination plants. Int. J. Artif. Intell. 2018, 16, 208-222.

68. Filip, F.G. Decision support and control for large-scale complex systems. Annu. Rev. Control 2008, 32, 61-70. [CrossRef]

69. Vaščák, J.; Rutrich, M. Path planning in dynamic environment using fuzzy cognitive maps. In Proceedings of the 6th International Symposium on Applied Machine Intelligence and Informatics, Herl'any, Slovakia, 21-22 January 2008; pp. 5-9.

70. Blažič, S. On periodic control laws for mobile robots. IEEE Trans. Ind. Electron. 2014, 61, 3660-3670. [CrossRef]

71. Kovács, B.; Szayer, G.; Tajti, F.; Burdelis, M.; Korondi, P. A novel potential field method for path planning of mobile robots by adapting animal motion attributes. Robot. Auton. Syst. 2016, 82, 24-34. [CrossRef] 
72. Ak, A.; Topuz, V.; Ersan, E. Visual servoing application for inverse kinematics of robotic arm using artificial neural networks. Stud. Inform. Control 2018, 27, 183-190. [CrossRef]

73. Costin, H.; Rotariu, C. Medical image analysis and representation using a fuzzy and rule-based hybrid approach. Int. J. Comput. Commun. Control 2006, 1, 156-162.

74. Kovács, L. Linear Parameter Varying (LPV) based robust control of type-I diabetes driven for real patient data. Knowl.-Based Syst. 2017, 122, 199-213. [CrossRef]

75. Precup, R.-E.; Teban, T.-A.; Albu, A.; Szedlak-Stinean, A.-I.; Bojan-Dragos, C.-A. Experiments in incremental online identification of fuzzy models of finger dynamics. Rom. J. Inf. Sci. Technol. 2018, 21, 358-376.

76. Andoga, R.; Főző, L.; Judičák, J.; Bréda, R.; Szabo, S.; Rozenberg, R.; Džunda, M. Intelligent situational control of small turbojet engines. Int. J. Aerosp. Eng. 2018, 2018, 8328792. [CrossRef]

77. Precup, R.-E.; Preitl, S. Development of fuzzy controllers with non-homogeneous dynamics for integral-type plants. Electr. Eng. 2003, 85, 155-168. [CrossRef]

78. Pozna, C.; Precup, R.-E.; Tar, J.K.; Škrjanc, I.; Preitl, S. New results in modelling derived from Bayesian filtering. Knowl.-Based Syst. 2010, 23, 182-194. [CrossRef]

79. Costa, B.S.J.; Angelov, P.; Guedes, L.A. Real-time fault detection using recursive density estimation. J. Control Autom. Electr. Syst. 2014, 25, 428-437. [CrossRef]

80. Nikolić, V.; Milovančević, M.; Petković, D.; Jocić, D.; Savić, M. Parameters forecasting of laser welding by the artificial intelligence techniques. Facta Univ. Ser. Mech. Eng. 2018, 16, 193-201. [CrossRef]

81. Osaba, E.; Carballedo, R.; Diaz, F.; Onieva, E.; Masegosa, A.; Perallos, A. Good practice proposal for the implementation, presentation, and comparison of metaheuristics for solving routing problems. Neurocomput. 2018, 271, 2-8. [CrossRef]

82. Chi, R.H.; Hou, Z.S.; Jin, S.T.; Huang, B. Computationally efficient data-driven higher order optimal iterative learning control. IEEE Trans. Neural Netw. Learn. Syst. 2018, 12, 5971-5980. [CrossRef] [PubMed]

(C) 2019 by the authors. Licensee MDPI, Basel, Switzerland. This article is an open access article distributed under the terms and conditions of the Creative Commons Attribution (CC BY) license (http://creativecommons.org/licenses/by/4.0/). 